\title{
STEREOGRAPHIC PROJECTION
}

\section{The Stereographic Projection}

By F. W. Sohon. Pp. ix +210 . (Brooklyn, N.Y.: The Chemical Publishing Co., Inc., 1941.) 4 dollars.

F W. SOHON, S.J., director of the Seismological - Observatory of Georgetown University, has written a very valuable book. This is a method of representing a solid body (usually figures on the surface of a sphere) on a plane, the centre of projection being a point on the surface of a sphere, and the whole sphere being represented once on an infinite plane. The projection has the merit that circles are represented as circles and that angles are retained. The book was not intended by the author to be exhaustive, but it contains a good selection of proofs, some by vector methods, and explicit applications to many problems including some in astronomy, hydrodynamics and seismology.

The seismological problem discussed by Sohon is the determination of the epicentre of an earthquake from a knowledge of its great circle distances from several seismograph stations by the semitangent method using geocentric latitudes (compression $\frac{1}{2} \frac{1}{97}$ ). The degree of accuracy of this method will naturally depend on the accuracy of the seismograph timing, the accuracy of the travel-time tables for the two pulses recognized, and the degree to which the depth of focus may be allowed for in computing the great circle distances.

The book is recommended to students and research workers in mathematics (especially geometry, differential geometry, complex variable and hydrodynamics), cartography, astronomy, seismology and crystallography. It is handy in form, well arranged, printed and produced, contains tables including stereographic projection elements for all seismograph stations computed by Weston-Woodstock students, and there is an adequate index.

E. T.

\section{POWER PLANT FOR AIRCRAFT}

Aircraft Engines

By A. W. Judge. Vol. 2. Pp. vii $+446+93$ plates. (London: Chapman and Hall, Ltd., 1941.) 30s. net.

$\mathrm{T}$ HIS is the second volume of what is intended to be a comprehensive treatise on aircraft engines and accessories. The first volume, reviewed in Nature of February 8 (p. 158), dealt largely with the factors which influence the performance of the engine under varying conditions of operation, but included also descriptive matter relating to carburetters, superchargers and cooling devices. The present volume deals mainly with engine types, details of construction, the remaining accessories, operation and testing.

Steady and rapid improvements in specific output and economy have taken place in recent years, largely due to supercharging, higher compression ratios, the use of light alloys and of hightension steels. In the twelve years prior to 1940 , speed has increased from 1,800 to 2,800 r.p.m., and piston speeds of more than $2,500 \mathrm{ft}$. per min. are now normal practice. Brake mean effective pressures have also increased from 125 to $220 \mathrm{lb}$. per sq. in. and more, so that the b.h.p. obtainable from a given cylinder capacity has increased by
150 per cent in this period. There is little doubt that these figures are conservative in relation to still more recent developments, and the author quotes brake mean effective pressures of more than $300 \mathrm{lb}$. per sq. in. at 2,400 r.p.m. which have been obtained from engines operated by sleeve valves.

In making comparisons between different types of engines, there are a number of important factors to be considered. These include power plant drag, moments of inertia of the engine about axes perpendicular to the axis of rotation, vulnerability to attack in the case of military aircraft, specific fuel consumption, specific weight, reliability under operation at full power for lengthy periods, accessibility for overhauls and adjustments, possible obstruction of view of pilot, convenience of attachment to fuselage, variations of torque reaction, cooling arrangements and silencing. The degree of complication involved will also influence the cost of manufacture and rate of output, in addition to increasing the necessary stock of spare parts. The relative importance of the different items will, of course, depend upon the nature of the duty for which the engine is designed, and this accounts to a large extent for the variations in size and type of the engines in actual use. 